\title{
Effect of temperature and mode of drying on bioactive compounds and quality of germinated parboiled rice
}

\author{
Klaykruayat, S. ${ }^{a}$; Mahayothee, B. $^{b^{*}}$; Nagle, M. ${ }^{\text { }}$; Müller, J. ${ }^{\text {a }}$ \\ ${ }^{a}$ Institute of Agricultural Engineering. Tropics and Subtropics Group. Universität Hohenheim, \\ Stuttgart, Germany. \\ ${ }^{b}$ Department of Food Technology. Faculty of Engineering and Industrial Technology. Silpakorn \\ University, Nakhon Pathom, Thailand. \\ ${ }^{c}$ Agricultural Research and Development Program. Central State University, Wilberforce, Ohio, \\ USA.
}

*E-mail of the corresponding author: mahayothee b@su.ac.th, busarakornm@yahoo.com

\begin{abstract}
Germinated parboiled rice (GPR) is recognized as a functional food because it is rich in bioactive compounds, especially gamma-aminobutyric acid (GABA). GPR was produced by soaking, incubating, steaming, and then drying using a high-precision hot air dryer. The results indicated that air flow mode and drying temperature had significant effects on the quality of GPR. Drying at higher temperatures and shorter times conserved GABA content. Using through-flow mode decreased drying time and prevented color change. However, a slightly lower percentage of head rice yield was observed. Moreover, using through-flow mode negatively affected the hardness loss after cooking.
\end{abstract}

Keywords: Germinated parboiled rice; Drying mode; Gamma-aminobutyric acid; Head rice yield 


\section{Introduction}

Germinated parboiled rice (GPR) is a product that can be promoted as a functional food. The characteristics of GPR are shorter cooking time, softer texture and higher contents of bioactive compounds than the normal rice. Nowadays, the GPR production in Thailand is performed by soaking paddy rice in water and then incubating until the radicle grows to a length of $0.5-1.0 \mathrm{~mm}$. After that, the germinated paddy is steamed until being cooked. Subsequently, the germinated parboiled paddy is sun dried to a final moisture content of $14 \% \cdot{ }^{[1]}$ Dried germinated parboiled paddy is dehusked, then the final product is packed.

During the germination, enzymes in paddy rice are activated and bioactive substances greatly increase. ${ }^{[2]}$ Gamma-aminobutyric acid (GABA) is a free amino acid, substantially increased by the germination process. ${ }^{[3]}$ GABA has a beneficial effect on human health, such as decreasing stress-related nerve impulses in the brain and promoting relaxation and sleep. ${ }^{[4]}$ Parboiling is a hydrothermal process, causing certain changes in paddy rice, including taste, texture, starch gelatinization, inactivation of enzymes, easier dehusking and increased head rice yield. ${ }^{[3]}$ Sootjarit et al. ${ }^{[5]}$ reported that germinated rice rapid drying at high temperatures $\left(80^{\circ} \mathrm{C}-140^{\circ} \mathrm{C}\right)$ resulted in a significant higher GABA content in comparison to drying at a lower temperature $\left(50^{\circ} \mathrm{C}\right)$. However, high temperature can easily cause overheating and cracking of grains which leads to low milling quality. ${ }^{[6]}$

Therefore, the suitable drying temperature for GPR production to conserve overall quality considering GABA content, milling and cooking properties is essential. Besides the drying temperature, the effect of air flow mode in the drying chamber is also important for efficient the drying process of a good quality GPR.

"Hom-Nil" is a pigmented Thai rice. It is also known as purple rice, that contains varieties of bioactive compounds such as antioxidants, phenolics, $\beta$-carotene and anthocyanins. ${ }^{[7]}$ Nowadays, it is commonly used for producing GPR in Thailand. Thus, the objective of this study was to study the effect of drying temperatures and modes of drying air on the GABA content and quality of germinated parboiled purple rice.

\section{Materials and Methods}

Thai purple paddy rice variety 'Hom Nil' with a moisture content of $11.28 \pm 0.28 \%$ (w.b.) was used in this study. Paddy rice was purchased from the farmer in Nakorn Pathom, Thailand and brought to Stuttgart, Germany by airfreight. It was cleaned to separate foreign matter before conducting the experiments.

\subsection{Preparation of germinated parboiled rice (GPR)}

Purple paddy rice 'Hom Nil' was soaked in water at $35^{\circ} \mathrm{C}$ for $24 \mathrm{~h}$ before draining then incubated at $35^{\circ} \mathrm{C}$ for $16 \mathrm{~h}$. Germinated paddy rice was then parboiled by steaming for 30 
min. The germinated parboiled paddy was dried under various conditions. Thin layer convective drying was conducted using a high-precision hot air laboratory dryer designed at the Institute of Agricultural Engineering, University of Hohenheim, Germany. ${ }^{[8]}$ Germinated parboiled paddy samples were dried under two different air flow modes, overflow (OF) and through-flow (TF), in a drying chamber (Fig. 1). Drying temperatures were varied at $40,50,60,70$ and $80^{\circ} \mathrm{C}$ with a constant specific humidity of $25 \mathrm{~g} / \mathrm{kg}$ dry air and an air velocity of $1.0 \mathrm{~m} / \mathrm{s}$. The temperature inside the germinated parboiled paddy was monitored by thermocouples inserted into the middle of rice kernels during the drying process. Drying was carried out until the moisture content of germinated parboiled paddy rice reached $13 \%$ (w.b.). Drying experiments were performed in triplicate. Dried germinated parboiled paddy was kept in vacuum-sealed aluminium foil pouches at $23 \pm$ $2^{\circ} \mathrm{C}$ and humidity of $52 \pm 3 \%$ for 1 day before dehusking. The husk was removed from kernel using a laboratory de-husker (TR250, Kett, Califonia, USA). One hundred grams of germinated parboiled rice (GPR) was then vacuum packed in aluminium foil pouches and kept at a temperature of $23 \pm 2{ }^{\circ} \mathrm{C}$ and humidity of $52 \pm 3 \%$ before quality analyses.

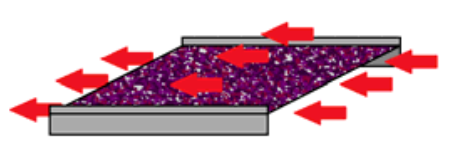

Over-flow mode (OF)

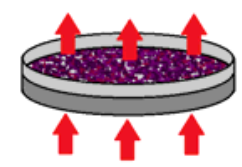

Through-flow mode (TF)

Fig. 1 Hot air direction in two air flow modes inside drying chamber of the dryer.

\subsection{Quality analyses}

\subsubsection{Head rice yield (HRY)}

After dehusking, the head rice yield was determined using the following formula: ${ }^{[9]}$

HRY $(\%)=($ mass of head rice $/$ mass of GPR $) \times 100$

\subsubsection{Color measurement}

A colorimeter (CR-400, Minolta Co., Ltd., Tokyo, Japan) was used to measure color of a whole kernel of dried GPR. Rice samples were filled in a petri dish with diameter of 100 $\mathrm{mm}$ and thickness of $15 \mathrm{~mm}$. Measurements were made with illumination area of $11 \mathrm{~mm}$ in five positions of a petri dish. The color values were reported in $\mathrm{L}^{*}, \mathrm{a}^{*}, \mathrm{~b}^{*}$ color coordination system with a D65 illuminant and $10^{\circ}$ observer.

\subsubsection{Texture analysis}

Hardness of cooked GPR was measured using a texture analyzer (TA-XT2i, Stable Micro systems, Surrey, UK) with slightly modified method of Srisang et al. ${ }^{[10]}$ Before testing, the 
samples were prepared by cooking $25 \mathrm{~g}$ GPR samples in a $250 \mathrm{~mL}$ beaker, with $75 \mathrm{~mL}$ distilled water about $30 \mathrm{~min}$. Ten of cooked rice kernels were selected from the center of the beaker after cooled at $23 \pm 2{ }^{\circ} \mathrm{C}$ for $30 \mathrm{~min}$. The cylindrical probe with a size of $50 \mathrm{~mm}$ was used for testing cooking characteristics. The peak force of the first compression is represented as hardness. The texture profile analysis was repeated five times per replicate.

\subsubsection{Determination of gamma-aminobutyric acid (GABA) content}

Sample extraction was performed with a modified method of Hayat et al. ${ }^{[11]}$ GPR samples were ground and sieved through $1 \mathrm{~mm}$ mesh. Five grams of ground sample were added 20 $\mathrm{mL}$ of $80 \%(\mathrm{v} / \mathrm{v})$ methanol and then homogenized for $3 \mathrm{~min}$. The suspension was centrifuged at $5000 \mathrm{rpm}, 4^{\circ} \mathrm{C}$ for $10 \mathrm{~min}$ and the supernatent was collected. Extraction steps were repeated twice then the whole supernatant was filtered through a $0.45 \mu \mathrm{m}$ of nylon membrane filter with vacuum pump. Supernatants were evaporated under a vacuum at $60^{\circ} \mathrm{C}$ using a rotary evaporator and adjusted to $5 \mathrm{~mL}$ using $80 \%$ methanol. The extracted solution was kept at $-18^{\circ} \mathrm{C}$ until analysis.

The GABA contents were determined by a HPLC (model RF-20A prominence, Shimadzu, Kyoto, Japan). The extracted solution $(1 \mathrm{~mL})$ was mixed with $1 \mathrm{~mL}$ of derivatizing reagent $(0.75 \%$ of 2-hydroxynaphthaldehyde) and $0.6 \mathrm{~mL}$ of borax buffer $(\mathrm{pH} 8.0)$. The reaction was performed at $80^{\circ} \mathrm{C}$ for $10 \mathrm{~min} \cdot{ }^{[12]}$ After the derivatization, chromatographic separation was done by a $\mathrm{C}_{18}$ column (Phenomenex, California, USA) at $30^{\circ} \mathrm{C}$ using methanol : water $(62: 38 \mathrm{v} / \mathrm{v})$ at a flow rate of $1 \mathrm{~mL} / \mathrm{min}$ as a mobile phase and detected by a diode array UV detector at $254 \mathrm{~nm}$. Results are expressed in mg GABA per $100 \mathrm{~g}$ (d.b.). Authentic GABA (Sigma-Aldrich, Munich, Germany) was used as a standard.

\section{Results and Discussion}

\subsection{Drying time}

After germination, samples absorbed water, and therefore, the moisture content increased from $11.28 \pm 0.28$ to $36.32 \pm 0.19 \%$ (w.b.). After steaming, the moisture content of paddy increased to $41.51 \pm 0.71 \%$ (w.b.). The drying times required for removing the water in parboiled germinated paddy to the moisture content of $13 \%$ (w.b.) at the drying temperatures of $40,50,60,70$ and $80^{\circ} \mathrm{C}$ in an OF mode were $390,195,130,100$ and 85 min, respectively, while in TF mode were 180, 110, 75, 55 and $45 \mathrm{~min}$, respectively. As expected, higher drying temperature reduced the drying time in both drying air flow modes. Drying using a TF mode shortened the drying time by about half compared to an OF mode at each temperature. This result could be explained by the more uniform airflow distribution in a drying chamber when using a TF mode compared with an OF mode. ${ }^{[13]}$ Uniformity of drying air velocity is known to improve the heat distribution. ${ }^{[14]}$ 


\subsection{Quality of dried GPR}

\subsubsection{Head rice yield}

Fig. 2 presents the temperatures of drying air, inside temperatures of GPR kernels during drying and the percentages of HRY after dehusking. For a TF mode, a slightly lower percentage of HRY was observed, as compared with the same drying temperature in an OF mode (Fig. 2 F). This present finding is consistent with other research which found that HRY decreased when drying temperature increased. ${ }^{[9]}$ This result can be explained in part by the kernel temperature of TF samples, which increased faster than those of OF samples at the same drying temperature (Fig. 2 A-E). This phenomena caused the cracking inside GPR kernels and lead to kernel breakage during dehusking. The findings are in agreement with Tirawanichakul et al. ${ }^{[15]}$ where the drying air temperature affected HRY of paddy.
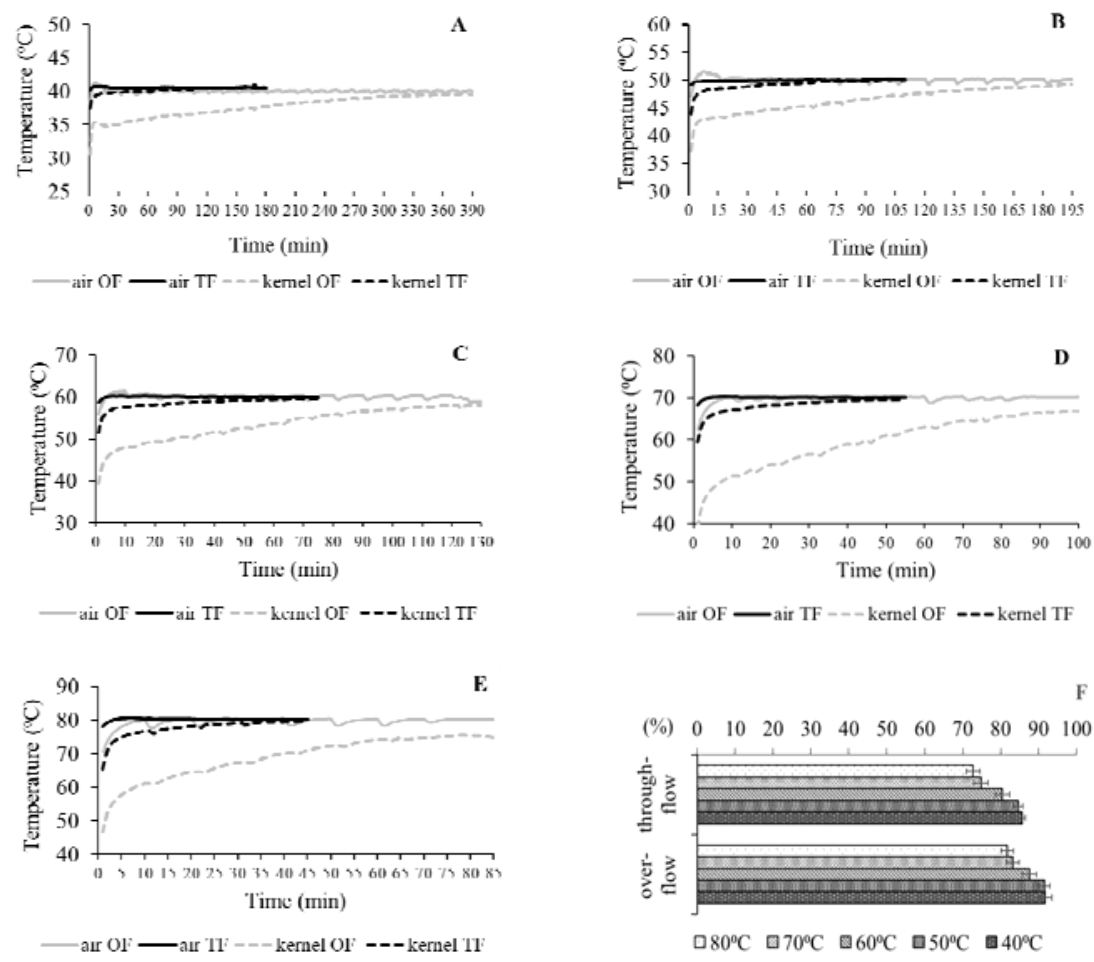

Fig. 2 Hot air and GPR kernel temperature during drying at $40^{\circ} \mathrm{C}(\mathrm{A}), 50^{\circ} \mathrm{C}(\mathrm{B}), 60^{\circ} \mathrm{C}(\mathrm{C}), 70^{\circ} \mathrm{C}$ $(D), 80^{\circ} C(E)$ and percentage of head rice yield $(F)$ in two airflow modes.

\subsubsection{Color of GPR}

In this study, airflow mode had a significant effect on color of GPR (Fig. 3). GPR obtained from the drying process with a TF mode had higher lightness $\left(\mathrm{L}^{*}\right)$ and redness $\left(\mathrm{a}^{*}\right)$ than 
using an OF mode. Comparing between two drying air flow modes, TF mode showed color values closed to the color of raw materials. The purple color of rice kernels is due to the presence of anthocyanin in the bran. ${ }^{[16]}$ Difference in color changes in these two airflow modes might be caused by different contact intensity between hot air and rice bran that affected the degradation of anthocyanin contents. However, the study of an impact of airflow modes on the anthocyanin contents in GPR is currently ongoing. Chen et al. ${ }^{[17]}$ reported that using different drying methods, significantly affects the rice color.

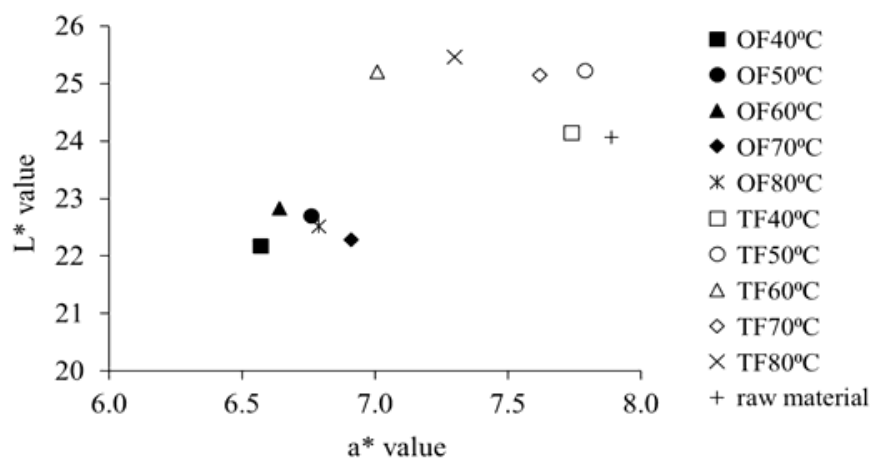

Fig. 3 Color of GPR obtained from drying at various drying temperatures in two airflow modes.

\subsubsection{Hardness of cooked GPR}

Hardness of cooked GPR was different among the difference drying conditions (Table 1). Hardness of dried GPR samples using OF mode was higher than TF mode. This study found a decreasing trend in hardness when increased drying temperature was used under both airflow modes. Drying GPR at 40 and $50^{\circ} \mathrm{C}$ in OF mode showed higher hardness than brown rice $(123 \pm 6 \mathrm{~N})$. However, higher drying temperature leads to the reduction of hardness after cooking. Cracking inside grain kernels could result in an increase of water uptake and consequently cause lower hardness in rice. This was confirmed by a percentage of HRY mentioned in previous section of this study.

Table 1. Hardness of cooked dried GPR at various drying temperatures in two airflow modes.

\begin{tabular}{ccc}
\hline Drying & \multicolumn{2}{c}{ Hardness (N) of cooked GPR } \\
\cline { 2 - 3 } Temperature $\left({ }^{\circ} \mathrm{C}\right)$ & over-flow & through-flow \\
\hline 40 & $140 \pm 6^{\mathrm{a}}$ & $111 \pm 4^{\mathrm{b}}$ \\
50 & $133 \pm 4^{\mathrm{a}}$ & $109 \pm 5^{\mathrm{bc}}$ \\
60 & $99 \pm 5^{\mathrm{d}}$ & $73 \pm 0^{\mathrm{e}}$ \\
70 & $101 \pm 8^{\mathrm{cd}}$ & $66 \pm 1^{\text {ef }}$ \\
80 & $94 \pm 1^{\mathrm{d}}$ & $60 \pm 1^{\mathrm{f}}$ \\
\hline
\end{tabular}

Data are the mean values \pm standard deviation and different letters indicate significant difference among mean values in lines and columns ( $\mathrm{P} \leq 0.05$ according to Duncan's test). 


\subsubsection{GABA content}

GABA content significantly increased after germination process and elevated again after parboiled process (Fig. 4A). After drying (Fig. 4B), GABA content decreased, especially after prolonged drying at low temperature. Drying at higher temperatures and shorter times prevented GABA degradation, especially at $80^{\circ} \mathrm{C}$. This finding is in agreement with Cheevitsopon and Noomhorm ${ }^{[18]}$ who showed drying temperature and time had significant effects on GABA content in rice. In addition, this study found that airflow modes did not significantly influence the levels of GABA.
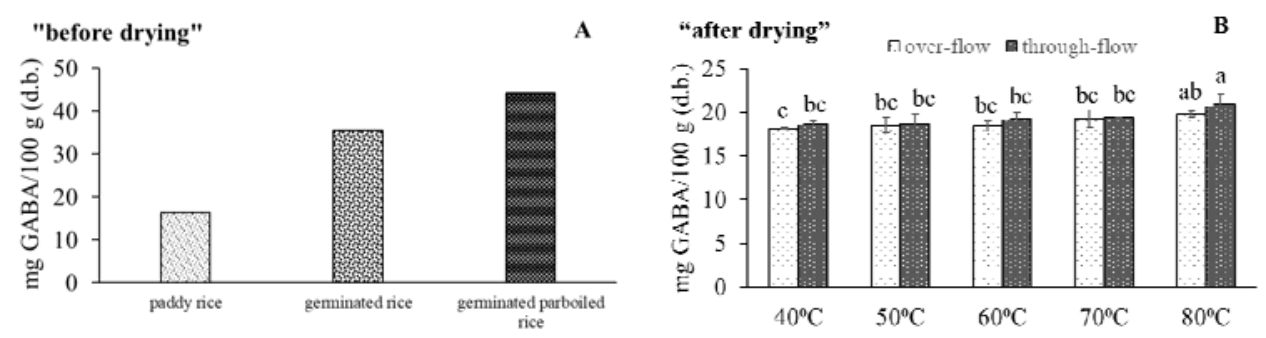

Fig. 4 GABA content of GPR dried at various temperatures in two airflow modes.

Values are the mean and bars indicate standard deviation and different letters indicate significant difference among mean values ( $P \leq 0.05$ according to Duncan's test).

\section{Conclusions}

The present study was designed to determine the effect of drying conditions on GABA content and quality of GPR. After drying, GABA content of all samples increased compared to the paddy rice due to the germination and steaming process. However, GABA content decreased after drying, especially after prolonged drying at low temperature. Overall, this study showed that GPR drying under the optimal drying conditions, namely using TF mode, significantly conserved color of GPR. However, using an TF mode at high drying temperature leads to low percentage of HRY and reduced hardness after cooking.

\section{References}

[1] Saerekui, P. Good manufacturing practices for germinated brown rice. Thai Agricultural Standard 2009, TAS 4404-2012, 79-83.

[2] Moongngarm, A.; Saetung, N. Comparison of chemical compositions and bioactive compounds of germinated rough rice and brown rice. Food Chemistry 2010, 122 (3), 782-788.

[3] Cheevitsopon, E.; Noomhorm, A. Effects of parboiling and fluidized bed drying on the physicochemical properties of germinated brown rice. International Journal of Food Science \& Technology 2011, 46 (12), 2498-2504.

[4] Dinesh Babu, P.; R. Subhasree, S.; Bhakyaraj, R.; Vidhyalakshmi, R. Brown ricebeyond the color reviving a lost health food - a review. Journal of Agronomy and Crop Science 2009, 2 (2), 67-72. 
[5] Sootjarit, S.; Jittanit,W.; Surojanametakul, V. Effects of drying methods on the nutritional and physical quality of pre-germinated rice. American Society of Agricultural and Biological Engineers 2011, 54 (4), 1423-1430.

[6] Hashemi, J. Investigation of fissure formation during the drying and post drying of japonica aromatic rice. International Journal of Agriculture and Biology 2008, 6, 179-184.

[7] Daiponmak, W.; Senakun, C.; Siriamornpun, S. Antiglycation capacity and antioxidant activities of different pigmented Thai rice. International Journal of Food Science \& Technology 2014, 49, 1805-1810.

[8] Argyropoulos, D.; Heindl, A.; Müller, J. Assessment of convection, hot-air combined with microwave-vacuum and freeze-drying methods for mushrooms with regard to product quality. International Journal of Food Science \& Technology 2011, 46, 333-342.

[9] Pruengam, P.; Soponronnarit, S.; Prachayawarakorn, S.; Devahastin, S. Rapid drying of parboiled paddy using hot air impinging stream dryer. Drying Technology 2014, 32 (16), 1949-1955.

[10] Srisang, N.; Prachayawarakorn, S.; Varanyanond, W.; Soponronnarits, S. Germinated brown rice drying by hot air fluidization technique. Drying Technology 2011, 29, 55-63.

[11] Hayat, A.; Jahangir, T. M.; Khuhawar, M. Y.; Alamgir, M.; Siddiqui, A. J.; Musharraf, S. G. Simultaneous HPLC determination of gamma amino butyric acid (GABA) and lysine in selected Pakistani rice varieties by pre-column derivatization with 2-Hydroxynaphthaldehyde. Journal of Cereal Science 2014, 60 (2), 356-360.

[12] Khuhawar, M. Y.; Rajper, A. D. Liquid chromatographic determination of gammaaminobutyric acid in cerebrospinal fluid using 2-hydroxynaphthaldehyde as derivatizing reagent. Journal of Chromatography B 2003, 788, 413-418.

[13] Udomkun, P.; Argyropoulos, D.; Nagle, M.; Mahayothee, B.; Janjai, S.; Müller, J. Single layer drying kinetics of papaya amidst vertical and horizontal airflow. LWT - Food Science and Technology 2015, 64, 67-73.

[14] Nagle, M.; González Azcárraga, J. C.; Mahayothee, B.; Haewsungcharern, M.; Janjai, S.; Müller, J. Improved quality and energy performance of a fixed-bed longan dryer by thermodynamic modifications. Journal of Food Engineering 2010, 99, 392-399.

[15] Tirawanichakul, S.; Prachayawarakorn, S.; Varanyanond, W.; Tungtrakul, P.; Soponronnarit, S. Effect of fluidized bed drying temperature on various quality attributes of paddy. Drying Technology 2004, 227 (7), 1731-1754.

[16] Hou, Z.; Qin, P.; Zhang, Y.; Cui, S.; Ren, G. Identification of anthocyanins isolated from black rice (Oryza sativa L.) and their degradation kinetics. Food Research International 2013, 50 (2), 691-697.

[17] Chen, X.; Qian, P.; Zhang, X.; Liu, F.; Lu, R. Improving instant rice quality by novel combined drying. Drying Technology 2014, 32,1448-1456.

[18] Cheevitsopon, E.; Noomhorm, A. Effects of superheated steam fluidized bed drying on the quality of parboiled germinated brown rice. Journal of Food Processing and Preservation 2015, 39, 349-356. 